\title{
O racismo gendrado do sistema penal
}

The gendered racism of the Criminal Justice System

\section{Luísa Rodrigues Torres}

\section{Autora}

luisa.rt@adv.oabrj.org.br

Graduada em Direito na PUC-Rio.

\author{
Thula Pires \\ Orientadora \\ thulapires@gmail.com \\ Doutora em Direito na PUC-Rio. \\ Coordenadora-Adjunta de Graduação e \\ professora de Graduação e Pós-graduação \\ do Departamento de Direito da PUC-Rio.
}

\section{Resumo}

Este trabalho visa questionar a imparcialidade do sistema penal diante das mulheres negras, considerando que elas correspondem à maioria das mulheres encarceradas. A criminologia é empregada para desnaturalizar este fato e evidenciar a seleção criminalizante exercida sobre um grupo que sofre as duas vulnerabilidades que compõem o racismo gendrado, ensejando em uma terceira vulnerabilidade, a perda da liberdade.

Palavras-chave: Direito a igualdade; racismo; machismo; sistema penal; criminologia.

\begin{abstract}
This paper purpose is to question the fairness of the Criminal Justice System towards black women, considering that they correspond to the majority of the female penitentiary population. Criminology is employed in order to denaturalize this fact and highlight the criminalizing selection promoted on a group who suffers the two types of vulnerability that make the gendered racism, resulting in a third type of vulnerability, the loss of freedom.
\end{abstract} Keywords: Equality rights; racism; sexism; Criminal Justice System; criminology. 


\section{A criminologia crítica e feminista aplicada na análise do racismo gendrado do sistema penal}

Este estudo tem como cerne a perspectiva da criminologia crítica e feminista brasileira sobre a relação entre o sistema penal e a mulher negra. A lei escrita, quando interpretada, tornase instrumento que pode ser adaptado a diversos objetivos. $\mathrm{O}$ intuito dessa pesquisa é averiguar se o Direito Penal brasileiro corrobora com o racismo gendrado ${ }^{1}$ infiltrado no pensamento coletivo. Trata-se de um estudo teórico, desenvolvido, principalmente, por meio de revisão bibliográfica. Fez-se, também, referência a bases empíricas, como levantamentos realizados por entes públicos e órgãos cuja atuação diz respeito à situação carcerária e pesquisas promovidas por investigadores relacionados a questão.

Inicialmente, importa conceituar o racismo gendrado. A relação das mulheres que são pretas com o Estado não reflete exatamente as questões do movimento negro e tampouco encontra identidade perfeita com as demandas feministas. Esta incompatibilidade percebida por Kimberlé Crenshaw a impulsionou a desenvolver o conceito de interseccionalidade entre as desigualdades de raça e gênero. A autora parte da premissa de que as minorias representativas, sujeitas a discriminação, não são perfeitamente separadas, pois há grupos em que opera a sobreposição de discriminações, como é o caso das mulheres negras. Tal sobreposição pode funcionar tanto como uma seleção de recorte, ou seja, especificamente direcionada a determinado grupo, quanto de forma combinada, quando a discriminação estrutural direcionada a aspectos distintos, como a raça e o gênero, prejudica mais aqueles que fazem parte dos dois grupos.

As mulheres negras são penalizadas por serem negras numa sociedade eurocêntrica, exescravista, racista. Da mesma forma, sofrem por serem mulheres em uma comunidade patriarcal, sexista. No movimento negro, não é despendida muita energia para tratar de questão exclusivamente femininas, como exames pré-natais, procedimentos de esterilização feminina, a relação trabalhista das domésticas. No movimento feminista, por sua vez, não se dá enfoque à supersexualização das mulatas, à valorização da beleza negra, ou à relação trabalhista das domésticas. Trata-se de um caso de intersecção entre grupos que afeta todo o contingente de mulheres negras, correspondente a cerca de $25 \%$ da população brasileira.

\footnotetext{
1 "Gendrado" é uma expressão consolidada por Teresa de Lauretis ao tratar de um espaço social em que se perpetua o discurso machista, reiterando a ideia de superioridade masculina e inferioridade feminina. (Cardoso, 2012, 126)
} 
Fato é que os estudos sociológicos acerca do papel da mulher negra na sociedade lhes atribuem reiteradamente três papéis. O de mãe preta, cuja imagem mais se assemelha à da escrava preta, pouco desejada, porém dedicada à servidão. O papel de mulata, associada ao carnaval, exótica e hiperssexualizada. E doméstica, representação mais recente, que pode ser vista como uma combinação das duas anteriores: delicada, destinada a serviços internos, mas, por estar inserida no cotidiano, perde a exoticidade. (GONZALES, 1984, p.8) Estas figuras, principalmente a da doméstica, prevaleceram em nossa sociedade.

Segundo o PNAD 2012, as mulheres pretas e pardas correspondem a 60,9\% das empregadas domésticas ${ }^{2}$. Ainda assim, não há grande interesse do movimento negro ou feminista em questionar este tipo de serviço. Caso as mulheres negras, domésticas, passem a ter mais inserção no mercado e assumam a responsabilidade pela subsistência familiar, os homens com quem se relacionam perderão um dos fatores que lhes garante a posição de opressores, ao invés de oprimidos. No caso das mulheres brancas, evidenciar a similaridade entre a escravidão e a relação trabalhista das domésticas causa mal-estar. Afinal, as domésticas foram um dos grandes pilares para a "alforria" das mulheres brancas que desejavam ter acesso ao mercado de trabalho, enquanto as domésticas cuidavam da casa de seus patrões. (SILVA, 2014, p.8) Isto revela a inércia, a desmotivação dos grupos superinclusos em extinguir a subordinação de grupos subinclusos.

Kimberlé Crenshaw conceituou os dois grupos tendo em vista o desenvolvimento do movimento negro e do movimento feminista negro. Tanto os homens negros quanto as mulheres negras sofrem com o racismo. Ocorre que este grupo, delimitado pela raça, admite subgrupos, estes ainda subordinados ao primeiro recorte. Esta subdivisão pode ser feita de acordo com vários critérios, como o gênero, sexo, idade. Assim, são obtidos diversos subgrupos, que não necessariamente corresponderão à minoria ou maioria. O contingente de mulheres negras, neste caso, não era valorizado, logo, foi estabelecida uma relação de superinclusão e de subinclusão. A superinclusão é direcionada aos homens negros que, dento do movimento negro, obtinham mais importância, mais voz, mais recursos. A subinclusão, então, era a das mulheres negras, que, a despeito de comporem um movimento contra a discriminação, eram submetidas ao sexismo. (CRENSHAW, 2002, p.4)

Veja-se: o objetivo deste trabalho é analisar a particularidade da relação entre a mulher negra e o sistema penal, se esse sistema de fato emprega uma perseguição mais intensa a elas. Sendo assim, é necessário o estudo da criminologia, para que haja esclarecimentos sobre o

\footnotetext{
2 Dados do IBGE, Pesquisa Nacional por Amostra de Domicílios 2008. 
alegado enfoque. Caso este enfoque seja revelado, a criminologia continuará sendo uma ferramenta, para explicar como os agentes penais selecionam mulheres negras para aplicar penas.

Para estudar o processo de criminalização, a Criminologia utiliza-se principalmente do método causal-explicativo. Ao ver de Sérgio Salomão Shecaira, trata-se de um nome genérico conferido a um grupo de temas estreitamente ligados: (i) a infração legal; (ii) os meios formais e informais de que a sociedade se utiliza para lidar com o crime com atos desviantes; (iii) a natureza das posturas com que as vítimas desses crimes serão atendidas pela sociedade; (iv) o enfoque sobre o autor desses fatos desviantes. (SHECAIRA, 2011, p.43)

Para desenvolver essa pesquisa, importa conceituar o Sistema Penal de que se trata. No livro "Direito Penal Brasileiro" Nilo Batista e Zaffaroni afirmam que sistema penal consiste no "conjunto de agências que operam a criminalização ou que convergem em sua produção". (ZAFFARONI, BATISTA, N., ALAGIA et al, 2011, p. 60) Tais agências são divididas conforme a sua atuação, como as políticas, que editam as leis penais, e as policiais, que promovem as investigações. Entende-se, portanto, que o sistema penal não se reduz à carceragem e compreende a produção de leis bem como a atuação de agentes privados, também.

Ressalta-se a relevante divergência doutrinária com relação ao estudo das leis penais. A Escola Interacionista, por exemplo, propunha uma atitude não valorativa perante condutas consideradas delitos e o afastamento dos estereótipos legais previstos nas codificações. Segundo esse raciocínio, a causa do delito não é o indivíduo, mas sim a lei, ao tornar a conduta um ilícito. A Criminologia Radical estendeu o questionamento teórico ao âmbito metodológico de aplicação do Direito Penal ao sustentar que a previsão legal de crime partia da ilusão de neutralidade do direito, de forma que seu efeito era o controle dos marginalizados. (SANTOS, J. 2006, p.36)

A Criminologia Crítica, mais moderna, foi apresentada por Taylor, Walter e Young, na década de 1960, ao publicarem uma obra que reunia artigos de diversos criminólogos cujo elemento comum era o materialismo histórico. Essa perspectiva superava o paradigma prático para tratar da ambiguidade dos conceitos de criminalização aplicados à parcela mais frágil da sociedade. (BATISTA, V., 2003, p.53)

Certo é que a Criminologia Feminista não se confunde com a Criminologia Crítica. A primeira foi desenvolvida por autoras feministas, principalmente na década de 1970, em que a produção acadêmica do movimento feminista ganhou fôlego. Destaca-se que assim como a Criminologia Crítica, a Feminista é composta de diversas perspectivas teóricas, mas que encontram premissas ou propostas em comum. Enquanto a criminologia crítica questiona o 
sistema penal do controle do desvio social, a criminologia feminista questiona o paradigma de gênero na produção do direito e da ciência moderna. (CAMPOS, 1999, p. 15) Ressalta-se que Carol Smart, apontada como fundadora da criminologia feminista, manifestou suas reservas acerca do que se chama de "agregação de variáveis", como raça e sexualidade, dentro de dois polos principais, homem e mulher, divididos pelo critério do gênero. (BARATTA, 1999, p. 33)

Às mulheres que delinquem, sofrem processos e são condenadas, é reservada uma reação própria. Quando essa pessoa delinque, ela quebra as diversas formas de controle que são exercidas sobre ela, logo, ela fica mais sujeita a sofrer a seleção que a levará à privação de liberdade. Nesse sentido, deve-se apontar o gritante aumento de presidiárias femininas.

O aumento da população carcerária feminina entre 2000 e 2016 foi de $656 \%$, enquanto a masculina foi de $293 \%$. Além disso, o Infopen-Mulheres informa que o aumento da taxa de aprisionamento feminina entre 2000 e 2016 foi de 525\%. A fim de apurar as particularidades do aprisionamento de mulheres negras, foram utilizados os dados do Infopen, levantamento nacional de informações penitenciárias, elaborado pelo Departamento Penitenciário Nacional (DEPEN), atualizado em junho de $2017^{3}$, bem como da segunda edição do Infopen-Mulheres ${ }^{4}$, fruto da mesma metodologia, mas aplicado às mulheres apenadas, publicado em $2018^{5}$.

Enquanto os negros e pardos correspondem a $56,1 \%$ da população brasileira, eles se fazem mais numerosos na população carcerária, na medida de $63,6 \%$ dos presos em geral e $62 \%$ das mulheres apenadas. Sob o enfoque da faixa etária, afirma-se que os jovens correspondem à maioria da população carcerária, vez que $29,9 \%$ do contingente aprisionado têm entre 18 e 24 anos. O percentual de mulheres encarceradas entre 18 e 24 anos guarda similar proporção, 27\%. Ocorre que os jovens com essa idade compõem apenas 10,9\% da sociedade brasileira. Os indivíduos que não têm o ensino fundamental completo correspondem à grande maioria dos aprisionados, em $51,3 \%$. Já os presos que possuem ensino superior completo representam $0,5 \%$ da população carcerária. As encarceradas que não concluíram o ensino fundamental são $45 \%$ da população carcerária, enquanto $1 \%$ delas possui ensino superior completo. Estes dados evidenciam a tendência do sistema penal brasileiro de punir os negros jovens sem educação básica, sem distinção de gênero.

\footnotetext{
${ }^{3}$ BRASIL. Ministério da Justiça. Levantamento Nacional de Informações Penitenciárias. Junho de 2017. Departamento Penitenciário Nacional, Ministério da Justiça, Brasília,

4 BRASIL. Ministério da Justiça. Levantamento Nacional de Informações Penitenciárias - Infopen Mulheres - Março de 2018. Departamento Penitenciário Nacional, Ministério da Justiça> Brasília,

${ }^{5}$ Acerca dessas pesquisas, destaca-se que são fruto da compilação dos registros dos sistemas prisionais de cada estado da Federação. Sendo assim, a precisão do Infopen é comprometida quando um estado não disponibiliza determinada informação, como o recorte de gênero sobre os aprisionados. Diante de estatísticas distintas sobre os mesmos quesitos, obtidas pelos dois levantamentos mencionados, optou-se por adotar as do Infopen-Mulheres, pois este trabalho é mais recente.
} 
Acerca da vulnerabilidade advinda do cárcere, destaca-se tese de Goffman sobre os 3 tipos de estigma. $\mathrm{O}$ primeiro é o conferido às abominações de corpo, deformidades físicas. $\mathrm{O}$ segundo corresponde às culpas de caráter individual, como paixões tirânicas, ou não naturais, e prisões. O terceiro diz respeito ao estigma da raça, nação, religião, classe, que podem ser transmitidos através de uma linhagem. (GOFFMAN, 1975, p.14) considerando o perfil da mulher encarcerada, que é o de marginalizada, negra, jovem, solteira, pobre, percebe-se o somatório dos dois últimos estigmas em um só indivíduo.

O perfil da encarcerada brasileira identifica a seleção de um número reduzido de pessoas ao qual será imposta uma pena, ou seja, revela o processo de criminalização conforme identificado por Nilo Batista. A criminalização apresentada por Nilo Batista admite as etapas primária e secundária. A criminalização primária, geralmente promovida pelos Poderes Legislativo e Executivo, se dá quando é sancionada uma lei penal material que autoriza a coação de determinadas pessoas para impô-las uma pena, ou seja, a incriminação de um grupo. A criminalização secundária, matéria do Poder Judiciário, ocorre quando a punição, de fato, é aplicada a um sujeito concreto.

Como é impossível efetivar perfeitamente todas as leis penais, a criminalização secundária é limitada, porque não é possível investigar, processar e punir todos os criminosos. Não existem recursos públicos suficientes para tanto. Isso gera a "cifra oculta da criminalidade", a enorme disparidade, indicada por pesquisas, entre o número de crimes cometidos e o número de crimes que chegam ao conhecimento público e levam à condenação. (THOMPSON, 2007, p.3) Isso se dá por diversas razões, entre elas, porque os delitos não são comunicados às autoridades, o arquivamento de sindicâncias ${ }^{6}$, e a absolvição sumária.

Então, a criminalização secundária passa a ser seletiva. Sobre essa seleção, deve-se afirmar que o feito não importa tanto quanto a forma como ele é comunicado, apresentado. Nilo Batista afirma que a seletividade do sistema penal é promovida tendo em vista (i) a criminalização conforme o estereótipo, (ii) a criminalização por comportamento grotesco ou trágico, e (iii) a criminalização devida à falta de cobertura.

A primeira forma de seleção encontra consonância com a tese de Lombroso ${ }^{7}$, pois associa um perfil biológico com a criminologia. Essa compreensão encontra perfeita aplicação na

\footnotetext{
${ }^{6}$ Admite-se $o$ arquivamento de sindicâncias, que possibilita à polícia o prosseguimento com o inquérito, ou não.

${ }^{7}$ Lombroso é reconhecido como responsável pela criação da criminologia como ciência em 1876, com a publicação de "O Homem Delinquente" (Leal, 2004, p.60). A tese de Lombroso consistia em um rígido determinismo biológico, que considera causas endógena como determinantes para identificação de criminosos.
}

DIGNIDADE RE-VISTA | ISSN2525-698X| 2020 | V. V | N. 9 ESP | Direitos Humanos, direitos para todos: pensando a igualdade material dos direitos. Pastoral Universitária Anchieta PUC-RIO. 
atuação do sistema penal com relação aos negros, que são mais apenados do que os brancos. A criminalização por comportamento grotesco ocorre se um sujeito que foge ao estereótipo atuar com brutalidade, atraindo atenção, como os homicidas familiares. A terceira forma de seleção reflete a situação em que alguém que detém um poder hegemônico perde uma disputa e, por isso, passa a sofrer vulnerabilidade. (ZAFFARONI, BATISTA, N., ALAGIA et al, 2011, p. 49)

Como a efetividade da criminalização secundária é limitada, há preferência em criminalizar aqueles que se encaixam num determinado perfil e evita-se criminalizar casos em que há dificuldade para promover tal correspondência. $O$ fato de a maioria das mulheres encarceradas ser negra, jovem, sem conclusão do ensino fundamental transparece a preferência do Estado em criminalizá-las. Sobre o tema, cabe destacar o que escreveu Nils Christie: "A fila não condiz com os estereótipos. Reconhecer a fila é reconhecer que os que estão nela não são perigosos, não são monstros. Eles vão para a prisão- ao final de algum tempo- mas não para proteger o público de sua presença" (CHRISTIE, 1998, p.29).

Ainda sobre a maioria dos encarcerados serem negros, deve-se abordar o conceito de racismo institucionalizado. $\mathrm{O}$ conceito de racismo institucional diz respeito a um pensamento intrínseco à sociedade sem que ninguém se esforce para mantê-lo, ou seja, sem atribuição de culpa. Wieviorka chama esse conceito de um "paradoxo insustentável", por implicar que aqueles que tiram proveito do racismo institucional não o percebem. A identificação do racismo institucional tem sua utilidade na revelação das formas veladas, naturalizadas do racismo, mas, em contraposição, busca eximir os autores dessa ideologia. (WIEVIORKA, 2007, p.32)

Os "crimes de colarinho branco", por exemplo, assumem um baixo índice de punição, visto que seus atores têm acesso a meios econômicos, que, por sua vez, geram acesso aos meios de comunicação, além do acesso à Justiça. $\mathrm{O}$ indivíduo marginalizado pela sociedade, por sua vez, corresponde o estereótipo criminal. Conforme Nilo Batista e Zaffaroni, os indivíduos recebem diferentes adestramentos para desenvolverem habilidades conforme a sua posição social, de forma que quando um sujeito comete um delito, o resultado deste delito refletirá os instrumentos advindos deste adestramento. Se estes forem primitivos, o delito será grosseiro, uma obra tosca. (ZAFFARONI, BATISTA, N., ALAGIA et al, 2011, p.54) O enquadre dos apenados quanto à sua escolaridade reitera a doutrina criminológica no sentido de afirmar que os sujeitos que se utilizam de instrumentos mais parvos cometem crimes fáceis de serem detectados e, por conseguinte, têm maior índice de penalidade.

Percebe-se, então, que a seletividade exercida pelo sistema penal conjuga diversas características, como a camada social, o biótipo do indivíduo, os instrumentos dos quais ele disponibiliza para executar o crime. Todos esses elementos reunidos geram flagrante 
desigualdade entre setores da sociedade. Essa afirmação é reiterada pelo seguinte trecho do Levantamento Nacional de Informações Penitenciárias, emitido em dezembro de 2014: "Como é sabido, após as sucessivas etapas - polícia, Ministério Público e judiciário - sobram os criminosos não brancos, do sexo masculino, mais pobres, menos escolarizados, com pior acesso a defesa e reincidentes."

A verdade é que a criminalização não espelha perfeitamente a gravidade do delito. $\mathrm{Na}$ impossibilidade de criminalização secundária tornar efetivas todas as prescrições feitas na criminalização primária, é feita uma diferenciação entre os que serão apenados e os que não o serão. E tal distinção se baseia em reiterar as estruturas sociais: os que estão à margem dos serviços públicos assim continuarão, e os que têm seus direitos assegurados os manterão

Importante elucidar que os apenados não o são pelo seu estado de vulnerabilidade à imposição estatal de uma pena. A vulnerabilidade, exclusivamente, não leva à punição de um cidadão. O processo penal exige que o indivíduo seja devidamente processado, the sendo assegurados os direitos a ampla defesa e ao contraditório, de forma que não seja levado à restrição de sua liberdade por um ilícito não cometido. A punição decorre da situação de vulnerabilidade que se dá quando há a chamada "situação de risco criminalizante", que é a posição concreta e risco criminalizante. Sendo assim, conclui-se: quem se encontra em estado de vulnerabilidade alto tem maiores chances de se encontrar em situação de criminalidade.

A seletividade do sistema penal não se restringe ao âmbito das penas, pois abrange a atuação do estado em perseguir, investigar, bem como a de policiar. O poder punitivo se faz mais presente nas áreas em que, tradicionalmente, há delitos contra a propriedade, logo, o Estado confere maior policiamento àqueles que detém propriedade. No Brasil, há casos em que a atuação policial se retira de regiões marginalizadas. Isso acarreta o desenvolvimento de um poder paralelo, organizado por agentes locais que fazem valer seu próprio ordenamento aos demais habitantes de comunidades por meio da força.

Cabe apontar o fenômeno chamado por Nilo Batista de "prisonização", que se desenvolve a noção de que só são aprisionados os responsáveis pelo cometimento de crimes graves, imorais. Isso se dá por um estímulo dos meios de comunicação, mas não reflete a realidade. A verdade é que praticamente $50 \%$ dos apenados sofrem penas por crimes com fins lucrativos: tráfico de drogas e roubos.Fato é que, no caso masculino, 31,88\% das penas de privação de liberdade se devem à prática de roubo, e 29,26\% ao tráfico de drogas. O grande responsável pelo aprisionamento de mulheres é o tráfico de drogas, que levou ao cárcere $64,48 \%$ das mulheres presas, sendo que apenas $15,72 \%$ das penas aplicadas a mulheres decorrem de crimes contra 0 
patrimônio. Importa destacar que enquanto 0,77 das penas aplicadas aos homens se deve a violência doméstica, só 0,11 das penas aplicadas a mulheres decorrem da Lei Maria da Penha.

Da mesma forma como há uma seletividade ao se estabelecer a criminalização, aplica-se uma apuração à vitimização. Quando é elaborada uma prescrição penal, incrimina-se o sujeito que adota determinada conduta e, simultaneamente, atribui-se o status de vítima ao sujeito passivo da conduta. Este processo corresponde à vitimização primária. A vitimização primária significa o reconhecimento da violação aos direitos de um cidadão e a criação de todo um procedimento tanto para preveni-la quanto para corrigi-la.

A vitimização secundária se dá quando o sujeito é, de fato, alvo de um crime. Se a criminalização secundária é restrita, o mesmo se dá para a vitimização secundária. Somente alguns delinquentes são apenados. Somente algumas vítimas são protegidas. (ZAFFARONI, BATISTA, N. ALAGIA, 2011, p. 54) A vitimização secundária, portanto, aflige principalmente os grupos que não são abarcados pelos serviços de segurança, ou que não contam com acesso ao Judiciário. Falta a prevenção ou a punição do ilícito penal. Ressalta-se que as mulheres negras são as maiores vítimas de crimes letais no país. Conforme o Atlas da Violência publicado pelo IPEA em 2019, entre 2007 e 2017 a taxa de homicídios de mulheres não negras cresceu $1,7 \%$ e de mulheres negras aumentou $60,5 \%$.

Além disso, o sistema penal brasileiro, em razão da alta criminalização de cidadãos, combinada com o baixo investimento em presídios, não respeita as determinações legais, e esta também é uma forma de vitimização secundária. Trata-se de prisões ilegais, que ensejam na violação de garantias processuais bem como de direitos fundamentais. O termo "superlotação de presídios" carrega diversos significados implícitos. Se um presídio recebe mais indivíduos do que o planejado, significa que não haverá o espaço adequado para o convívio saudável.

A Lei de Execuções Penais, em seu art. $3^{\circ}$, comanda que serão assegurados aos apenados todos os direitos que não sejam afetados pela pena em si. Dessa forma, figura o direito à vida, por exemplo, pela vedação à prisão de morte, fixada pelo art. $5^{\circ}$, XLVII, CRFB88. A despeito da previsão legal, são registrados óbitos nos cárceres. Enquanto no Brasil, a taxa de mulheres mortas em 2015 foi de 4,5 por ano, para cada grupo de 100 mil mulheres, no sistema prisional, essa taxa chega a 5,7 mulheres mortas para cada 100 mil mulheres presas. A probabilidade de um indivíduo ser corrigido enquanto privado de sua liberdade e de sua privacidade, em um ambiente superlotado, e provavelmente insalubre, é pequena.

Para abordar a execução da prisão feminina, deve-se atentar à forma como os estabelecimentos prisionais brasileiros foram instalados no Brasil. Um dos primeiros registros que se tem sobre mulheres brasileiras aprisionadas é de 1870, quando foi elaborado o Relatório 
do Conselho Penitenciário do Distrito Federal. Tal relatório indicou que entre 1869 e 1870, 187 mulheres escravas haviam passado pelo sistema penal. (ILGENFRITZ E SOARES, 2002, p. 52) Deve-se atentar ao fato de que esse registro reflete a relação já estabelecida entre as mulheres negras e o Sistema Penitenciário feminino: a punição é direcionada aos corpos negros.

As mesmas autoras mencionam a análise elaborada por Lemos de Brito das prisões-navio, uma das primeiras formas de prisão aplicadas no Brasil. Nesse caso, as mulheres eram presas junto aos homens e escravos ${ }^{8}$ em navios. (ILGENFRITZ E SOARES, 2002, p. 52) O Estado brasileiro, inicialmente, não se preocupou em construir estabelecimentos penitenciários femininos. Fato esse reflete a doutrina Criminológica Crítica, que aponta a ideia de que mulheres são mais frágeis que homens, logo, sofrem mais a vitimização do que a criminalização. A Criminologia Crítica se revelou uma ciência multidisciplinar que congrega diversos ramos do conhecimento. Esta forma contemporânea de estudo passou a abranger, também, as vertentes psicológica e sociológica do crime, observando-o como sintoma de uma sociedade contraditória. (ZAFFARONI, BATISTA, N., ALAGIA et al, 2011, p. 284)

O Sistema Carcerário feminino, no Brasil, foi construído tendo como base os estabelecimentos direcionados a homens. Com relação às motivações aventadas para a criação de estabelecimentos separados dos masculinos, existem duas vertentes. A primeira concerne ao comportamento masculino diante da presença feminina, tida como influência perniciosa aos condenados. (ILGENFRITZ E SOARES, 2002, p. 58) A segunda diz respeito às condições do cárcere feminino. O aprisionamento dos dois gêneros no mesmo espaço demonstrou-se maléfico física e moralmente às mulheres, de acordo com Lemos de Brito. (ILGENFRITZ E SOARES, 2002, p. 52)

Certo é que, considerando que as necessidades dos dois gêneros não são iguais, conferirlhes estabelecimentos idênticos, ainda que separados, não seria o suficiente para adequá-los. Mulheres dependem de acompanhamento ginecológico e maternidades, por exemplo. Nesse sentido, a Lei de Execuções Penais, em seu art. 82, prevê o recolhimento de mulheres a estabelecimentos penais próprios e adequados às suas condições pessoais, como berçários. Fato é que elas continuam obrigadas a se adaptar a prisões inadequadas ${ }^{9}$. De todas as unidades prisionais cadastradas no Infopen-Mulheres de 2018, 74\% são masculinas, 7\% são femininas e $16 \%$ são mistas.

\footnotetext{
${ }^{8}$ Nessa época prevalecia o entendimento de desumanidade dos escravos.

9 Brasil. Presidência da República. Secretaria Especial de Políticas para as Mulheres. Grupo de Trabalho Interministerial - Reorganização e Reformulação do Sistema Prisional Feminino (relatório final). Brasília. Presidência da República, 2008. 196 p.
} 
Em dezembro de 2016, existiam 726.354 pessoas privadas de liberdade no Brasil e um déficit de 303.112 vagas para alocar este número de encarcerados. Isso quer dizer que a taxa de ocupação média das carceragens e delegacias brasileiras correspondia a 171,62\%. Com uma população prisional tão alta, a demanda por vagas no sistema carcerário corresponde a quase o dobro das vagas existentes, sendo que todos os estados da federação possuem déficit de vagas em seus respectivos sistemas prisionais. Ademais, entre 2000 e 2017, a população carcerária aumentou cerca de $155 \%$.

Apenas 55 unidades em todo o país que declararam apresentar cela ou dormitório para gestantes, sendo que existem 886 gestantes e lactantes em regime de privação de liberdade, de forma que somente $50 \%$ delas está em estabelecimento que tem cela adequada. Com relação a berçários, ou centros de referência materno-infantil, que compreendem os espaços destinados a bebês com até 2 anos de idade, só $14 \%$ das unidades femininas ou mistas afirmaram tê-los. Sendo que as unidades femininas ou mistas que têm espaços de creche destinados a receber crianças acima de 2 anos correspondem a 3\% de todos os centros penitenciários femininos ou mistos.

Apesar de a gravidez ser uma questão exclusiva das mulheres, o Infopen-Mulheres não disponibiliza informações sobre as detentas gestantes e seus filhos. Sendo assim, utilizou-se os dados fornecidos pelo Relatório Final do GTI-SPM ${ }^{10}$ e pelo Relatório da OEA sobre Mulheres encarceradas no Brasil, também apresentado em $2007^{11}$. O Relatório do GTI-SPM indica que as presas não têm atendimento pré-natal adequado, que não há padronização do tempo de convívio garantido entre mãe e filho entre as unidades carcerárias e que a mãe perde o vínculo com a criança recém-nascida ${ }^{12}$. O Relatório da OEA afirma que a maioria das gestantes não realiza exames laboratoriais, que a internação pós-parto não é assegurada e que a maior parte dos berçários existentes são celas improvisadas, mas ainda insalubres. Ademais, o trabalho da OEA aponta não ser raro um parto ocorrer nos pátios ou celas dos cárceres.

No caso específico do Rio de Janeiro, a pesquisa "Mulheres e crianças encarceradas" ${ }^{13}$, realizada entre junho e agosto de 2015, indicou que o seguinte perfil para as gestantes

10 A metodologia de trabalho empregada pelo Grupo baseou-se em depoimentos e relatos de profissionais da área jurídica, representantes de entidades e órgãos envolvidos com a temática, representações da sociedade civil e do Conselho de Comunidade, em visitas a presídios femininos, em pesquisas, documentos e na análise da legislação vigente.

11 Foram utilizados dados de acesso público e foram tecidas considerações sobre as diferentes realidades no sistema carcerário nas diversas regiões do país.

${ }_{12}$ A Lei 11942, de 2009, prevê que o bebê permaneça com a mãe encarcerada por ao menos 6 meses. Tal previsão legal, no entanto, é posterior à elaboração do Relatório GTI-SPM. De qualquer forma, não são oferecidos dados que comprovem a alteração do panorama vigente em 2007.

${ }^{13} \mathrm{https}$ //drive.google.com/file/d/0B6311 AmqcdPVRmIXb25wakx2TVE/view?pref=2\&pli=1

DIGNIDADE RE-VISTA | ISSN2525-698X| 2020 | V. V | N. 9 ESP | Direitos Humanos, direitos para todos: pensando a igualdade material dos direitos. Pastoral Universitária Anchieta PUC-RIO. 
aprisionadas: $78 \%$ são jovens, $77 \%$ são negras ou pardas, $82 \%$ delas são solteiras e $75,6 \%$ têm baixa escolaridade. Ademais, a maioria das detentas que respondeu a pesquisa disse ter sido aprisionada já grávida ${ }^{14}$. Entre as entrevistadas, 53\% não receberam atendimento ginecológico. Com relação às visitas, a investigação apontou que 65,9\% das presidiárias grávidas não recebe visitas. Entre as que recebem visitas, 50\% são visitadas pelas mães e 14,3\% recebem seus maridos ou companheiros.

$\mathrm{O}$ fato de haver mais locais próprios para visitas em unidades penitenciárias femininas ${ }^{15}$ não significa que elas recebam mais visitas íntimas. Nos estabelecimentos masculinos, registrou-se a média de 7,8 visitas por pessoa ao longo do semestre, enquanto nos estabelecimentos femininos e mistos, essa média corresponde a 5,9 por pessoa privada de liberdade. Por exemplo, o Censo Penitenciário de São Paulo, realizado em 2002, afirma que somente $17,9 \%$ das presidiárias costumavam receber visitas de seus companheiros, enquanto a taxa de presidiários que recebiam visitas de suas mulheres era de 64,1\%. (LIMA, 2006, p.63)

A manutenção de contato entre as mulheres encarceradas e o mundo de fora é muito custoso, sendo possível identificar empecilhos impostos pelo próprio sistema penal. Iniciativas que poderiam ser tomadas para não privar a encarcerada de manter contato com seus familiares, como a busca pelos dados de seus parentes, não são tomadas. O relatório temático "Mulheres, Meninas e Privação de Liberdade", elaborado pelo MEPCT em 2016, evidencia isso: "muitas disseram que não recebem visitas pelo fato de não terem conseguido informar os familiares, outras nos repassavam os telefones de seus familiares para que entrássemos em contanto" (Rio de Janeiro. B, 2016, p.42).

A ausência de visitas às mulheres não só é socialmente e psicologicamente custosa. Existem consequências físicas. Como as cadeias brasileiras carecem de infraestrutura e serviços, é frequente que os visitantes sejam os responsáveis por fornecer o mínimo necessário. O relatório "Mulheres, Meninas e Privação de Liberdade no Rio de Janeiro" também disponibiliza informações nesse sentido: "Cabe ressaltar, que a roupa de cama, acessórios, roupa intima são trazidos por parentes, as presas que não recebem visitas ficam sem receber

\footnotetext{
${ }^{14}$ A Lei 12. 403/2011 prevê a possibilidade de substituição da prisão preventiva nos casos de gestantes a partir do $7^{\circ}$ mês de gestação, quando a gravidez for de alto risco e também no caso de pessoas indispensáveis aos cuidados de crianças menores de 6 anos ou que necessitem de cuidados especiais. Trata-se de uma possibilidade sujeita à discricionariedade do juiz, no entanto.

${ }^{15}$ As unidades prisionais masculinas que contam com espaços especificamente destinados a visitações e outras atividades sociais correspondem a $34 \%$ do total. Os estabelecimentos prisionais femininos que dispõem desse ambiente, por sua vez, significam $50 \%$ das unidades femininas. No caso dos estabelecimentos mistos, a proporção é de 30\% com infraestrutura para tal. Ademais, $41 \%$ das unidades presidiárias femininas e $34 \%$ das unidades prisionais mistas possuem espaço específico para a visitação íntima.
}

DIGNIDADE RE-VISTA | ISSN2525-698X| 2020 | V. V | N. 9 ESP | Direitos Humanos, direitos para todos: pensando a igualdade material dos direitos. Pastoral Universitária Anchieta PUC-RIO. 
tais acessórios, e na maioria das vezes as internas compartilham tais itens". (Rio de Janeiro. B, 2016, p.38)

A questão das visitas íntimas é mais complexa. Inexiste legislação federal regulamentando a concessão de visitas íntimas. Dessa forma, essa visita é regulada por dispositivos legais estaduais. O art. 67, I, "b", do Regulamento do sistema penal do Estado do Rio de Janeiro, o Decreto Estadual no 8.897/86, determinou que a visita íntima é uma regalia a ser concedida gradativamente. Segundo o art. 20 da Resolução SEAP RJ nº 395, de 21 de março de $2011^{16}$, o preso só poderá receber visita íntima se for legalmente casado. Além disso, para que se promova o credenciamento como companheiro/cônjuge junto à Secretaria de Estado da Administração Penitenciária do Rio de Janeiro, deve ser apresentada ou a certidão de casamento ou a declaração de união estável.

Ocorre que 57\% das presidiárias são solteiras, então tal regalia somente é disponibilizada a menos da metade das presidiárias. A possibilidade de presidiárias exercerem sua sexualidade fora de casamento ou união estável não é admitida. A título de ilustração, cabe reproduzir um trecho do relatório "Mulheres, Meninas e Privação de Liberdade": "Diferente dos homens, as mulheres quase não recebem visitas, a maioria é abandonada por seus companheiros, apenas $1 \%$ realizam a visita íntima, a solidão é ainda mais marcante no presídio feminino." (Rio de Janeiro. B, 2016, p.94)

O regulamento não estipula qualquer distinção entre o direito de presidiários ou presidiárias à visita. A despeito da igualdade formal, os servidores das unidades penitenciárias atribuem tratamento distinto aos dois sexos. Drauzio Varella afirma ter colhido relatórios segundo os quais as visitas íntimas começaram nos anos 80, com barracas improvisadas nos pátios dos pavilhões em dias de visita, mas quando surgiram as primeiras queixas envolvendo menores de idade, as autoridades resolveram oficializar as visitas íntimas, que passariam a depender de determinada burocracia (VARELLA, 2007, p.60).

Considerando a data em que foi emitida a Resolução $n^{\circ} 1 / 1999$ do CNPCP, que recomenda que os Departamentos Penitenciários Estaduais ou órgãos congêneres de São Paulo assegurem o direito à visita íntima aos presos de ambos os sexos, percebe-se que a visita íntima foi assegurada aos homens antes de às mulheres, informalmente. Ademais, nota-se que aos homens, é atribuído o direito à sexualidade sem que sejam observadas a certidão de casamento ou declaração de união estável, enquanto essa apresentação é imposta às mulheres.

\footnotetext{
${ }^{16}$ As condições para que a benesse fosse concedida já haviam sido dispostas na Resolução SEAP RJ ำ 142 /2006

DIGNIDADE RE-VISTA | ISSN2525-698X| 2020 | V. V | N. 9 ESP | Direitos Humanos, direitos para todos: pensando a igualdade material dos direitos. Pastoral Universitária Anchieta PUC-RIO.
} 
Sobre esse tema, é imperativo apontar a teoria do "labeling approach" ou "etiquetamento". Tal teoria altera o enfoque sobre o delinquente e o fixa no sistema penal. A concepção mencionada é dominada por duas correntes da sociologia americana. A primeira, é a do Interacionismo Simbólico, inspirada em George H. Mead ${ }^{17}$. Sua proposta é a observação da realidade social como resultado de inúmeras interações concretas entre indivíduos. A tipificação de uma dessas interações lhe confere um valor que se perpetua através da linguagem. A segunda é a da etnometodologia, inspirada nas anotações de Alfred Schutz. Para a etnometodologia, a realidade social advém de uma construção social que tem como um de seus alicerces a tipificação produzida por parte de indivíduos e diferentes grupos. A teoria do "labeling approach", portanto, promove a compreensão do criminoso como fruto da experiência de criminalização, e não como uma realidade pré-constituída. (BARATTA, 2002, p.85)

A criminalização é consequência de um delito, mas provoca por si só outros efeitos. $\mathrm{O}$ indivíduo que é criminalizado é estigmatizado de forma permanente. Há que se pensar que, no caso feminino, o fato de criminalidade não ser esperada, a reação será ampliada. A mulher que comete ilícitos se distancia da subcultura, e por isso, lhe são aplicadas inúmeras sanções sociais.

As mulheres que se relacionam com detentos ainda se deparam com um serviço penitenciário ofensivo. A revista realizada com o objetivo de garantir a segurança e os bons costumes na unidade carcerária ${ }^{18}$ era feita de forma humilhante, por isso era conhecida como "revista vexatória". A rispidez com a qual o procedimento era guiado não o tornaria mais eficaz em evitar que se entrasse com armas ou drogas escondidas no corpo. Ocorre que a Constituição federal proíbe que a pena passe da pessoa do condenado, o que levou à aprovação da Lei 13.271/2016 vedando a revista íntima em ambientes prisionais.

Ademais, deve-se ter em mente as mulheres visitantes, que mantêm um relacionamento com um presidiário, seja ele romântico ou parental. Nos dois casos, as mulheres sofrem um "etiquetamento", atraindo, portanto, a seletividade do sistema penal. Sua proximidade com um delinquente, manutenção da relação e o contato com um presídio levam à compreensão de que são "potenciais criminosas" e a elas é aplicada uma reação proporcional à imoralidade do delito

17 Filósofo americano da Escola de Chicago, defendia o pragmatismo.

${ }^{18}$ A Portaria DEPEN №132/2007 determinava em seu art. 3ำ que somente se aplicasse a revista manual em caso de "fundada suspeita de que o revistando traga consigo objetos, produtos ou substâncias, cuja entrada seja proibida legalmente e/ou exponha a risco a segurança do estabelecimento penal federal". Ademais, seu 5o proibia, no âmbito das penitenciárias federais, a revista íntima nos visitantes. Tal Portaria determinava que a revista fosse realizada por servidor habilitado e do mesmo sexo do visitando, e tendo em vista a dignidade humana. Caso fosse necessário o toque durante a revista, deveria ser chamado um profissional habilitado da área de saúde. A Portaria DEPEN no 157/2007, que regulamenta as revistas para acesso às penitenciárias federais, revogou a Portaria no132 e especificou, em seu art. $3^{\circ}$, que "A revista manual deverá ser realizada em todos aqueles que desejarem ter contato direto com o preso durante a visita social ou íntima." 


\section{DIGNIDADE}

cometido pelo apenado. As consequências do estigma de "mulher ou mãe de bandido" não se limitam à revista vexatória. Nem todos os detentos podem trabalhar ou conseguem alguma atividade laborial remunerada. Dessa forma, o detento deixa de ser uma fonte de renda para significar uma despesa. Outrossim, com relação às mães dos filhos dos presos, restará o pagamento pela educação e alimentação dos filhos a ser suportado por só uma pessoa. (CORREA, 2017, p.18)

Quanto pior tiver sido o crime cometido pelo apenado, mais definitivo será o "etiquetamento" dos que com ele se relacionam. Trata-se de uma transferência da pena. Em se tratando de um laço amoroso, a análise dos estigmas segundo Goffman aponta a cumulação de uma paixão tirânica e a potencial criminalização. Caso a situação seja de maternidade, entendese que a culpa será atribuída por ter criado um marginal.

\section{Conclusão}

A Criminologia se difere do Direito Penal como ciência no sentido de que o Direito Penal busca um ideal, uma prescrição para que a sociedade viva em harmonia, enquanto a Criminologia reflete a realidade. Há uma contraposição entre "o que deve ser" e "o que realmente é", mas a Criminologia se faz necessária para que haja compreensão do quão efetivo é o Direito Penal e de quais são os meios para torná-lo efetivo. O sentido estrito de Criminologia se restringe ao estudo empírico do delito e da personalidade do delinquente. Já seu sentido lato engloba o conhecimento sobre a conduta criminosa, a criminalização, sua prevenção, além dos mecanismos de controle policiais ou jurídicos. (PRADO, 2012, p.73)

O levantamento de dados é uma forma isenta de expor a preferência do sistema penal punir mulheres negras. Considerando o cenário em que o Estado se revela tirano, é facilitado o reconhecimento da perseguição direcionada a essas mulheres. Diante de um quadro tão estático, as Criminologias Crítica e Feminista apontam a seletividade do Estado no momento de perseguir indivíduos negros, jovens, de baixa escolaridade. Note-se que, a despeito de as mulheres negras corresponderam a minoria da população presidiária, a verdade é que elas são as mais vitimadas, ou seja, o sistema penal tende a persegui-las, penalizá-las, bem como a se omitir da obrigação de garantir-lhes segurança. Trata-se de uma sub-minoria cujas demandas são suprimidas.

Certo é que a perda da liberdade decorrente da condenação da mulher negra enseja em estigmatização, o que leva a uma tripla vulnerabilidade mantida ao longo da história. Difícil 
não associar a imagem das mulheres negras encarceradas à imagem das escravas da época colonial. A liberdade lhes é negada, assim como a salubridade, higiene e dignidade humana. Seus filhos são afastados desde cedo, da mesma forma. O sistema penal brasileiro não oferece escapatória para as mulheres que tem contato com ele. As mulheres que se relacionam com presos, em sua maioria negros e pobres, também são estigmatizadas e passam a ser escravas da pena direcionada ao homem com quem se relacionam.

A Criminologia Feminista propõe a mudança de paradigma de gênero para interromper o ciclo de violações perpetuadas pelo sistema penal, revelado pela aplicação da Criminologia Crítica, e serve de instrumento para evidenciar as particularidades das mulheres negras encarceradas. Promovendo o conhecimento acerca de violações que apenas esta minoria sofre, possibilita a elaboração de correções, soluções para as questões das mulheres negras em privação de liberdade. 


\section{Referências bibliográficas}

BATISTA, Vera Malaguti. Difíceis ganhos fáceis: Drogas e Juventude Pobre no Rio de Janeiro. Coleção pensamento Criminológico. Rio de Janeiro: Ed. Revan. 2a ed. 2003.

BARATTA, Alessandro. O paradigma do gênero: Da questão criminal à questão humana. In: CAMPOS, Carmen Hein de. (Org.) Criminologia e Feminismo. Porto Alegre: Sulina, 1999. p.19-80.

CARDOSO, Claudia Pons. Outras falas: Feminismos na perspectiva de Mulheres Negras Brasileiras. Tese (doutorado). Universidade Federal da Bahia. Faculdade de Filosofia e Ciências Humanas. Bahia, Salvador, 2012.

CAMPOS, Carmen Hein de. Introdução. In: CAMPOS, Carmen Hein de. (Org.) Criminologia e Feminismo. Porto Alegre: Sulina, 1999. p.13-18.

CEJIL et al. Relatório sobre as mulheres encarceradas no Brasil, 2007.

CHRISTIE, Nils. A Indústria do Controle Do Crime: a caminho dos GULAGs em estilo ocidental. Rio de Janeiro: Forense, 1998. 227p.

CORREA, Catalina Perez, The foundations of modern criminal law and gender equity.

CRENSHAW, Kimberlé. Documento para o Encontro de Especialistas em Aspectos da Discriminação Racial Relativos ao Gênero. 2002

GONZALES, Lélia. Racismo e sexismo na sociedade brasileira. In: Revista Ciências Sociais Hoje, Anpocs, 1984, p. 223-244.

GOFFMAN, Erving. Estigma: notas sobre a manipulação da identidade deteriorada. Rio de Janeiro: Zahar 1975. 158p.

LIMA, Márcia de. Da visita íntima à intimidade da visita: a mulher no sistema prisional. Dissertação (mestrado) Faculdade de Saúde Pública, Universidade de São Paulo, São Paulo. 2006.

RIO DE JANEIRO (Estado). Assembleia Legislativa do Estado do Rio de Janeiro. Mecanismo Estadual de Prevenção e Combate à Tortura. Relatório Anual de 2012. Rio de Janeiro: ALERJ, 2012.

SANTOS, Juarez Cirino dos. A Criminologia Radical. $2^{\text {a }}$ ed. ed. Lumen Juris. 2006.

SHECAIRA, Sergio Salomão. Criminologia. 3. ed. rev., atual. e ampl. São Paulo: Revista dos Tribunais, 2011.414 p.

SILVA, Joselina da. I Encontro Nacional de Mulheres Negras: o pensamento das feministas negras na década de 1980. In: SILVA, Joselina da; PEREIRA Amauri Mendes. O Movimento das Mulheres Negras. Belo Horizonte: Ed. Nandyala, 2014. p.8. 2014 
SOARES, Barbara Musumeci; ILGENFRITZ, Iara. Prisioneira: Vida e violência atrás das grades. Rio de Janeiro: Garamond, 2002.

THOMPSON, Augusto. Quem são os criminosos: o crime e o criminoso: entes políticos. 2. ed. Rio de Janeiro: Lumen Juris, 2007. 178 p.p.39

VARELLA, Drauzio. Estação Carandiru. São Paulo: Companhia das Letras, 1999.

WIEVIORKA, Michel. Racismo, uma Introdução. Editora perspectiva. São Paulo. Tradução de Fany Kon. 2007

ZAFFARONI, E. Raúl; BATISTA, Nilo; ALAGIA, Alejandro; SLOKAR, Aejandro. Direito Penal Brasileiro: primeiro volume- Teoria do Direito Penal. Rio de Janeiro: Revan, 2003, $4^{\text {a }}$ ed. maio de 2011. 660 p. 